\title{
Effects of Pulse Sounds on Escape Behavior of False Killer Whales
}

\author{
Tomonari Akamatsu, ${ }^{* 1}$ Yoshimi Hatakeyama, ${ }^{* 1}$ and Naoyuki Takatsu*2 \\ (Received December 24, 1992)
}

\begin{abstract}
We observed the behavior of two false killer whales Pseudorca crassidens in response to a variety of underwater pulsed sounds. The whales were kept in a net enclosure. We employed 15 different kinds of sounds and carried out 68 experiments. The behavior of the false killer whales after the sounds were transmitted was divided into three categories: "effective", "somewhat effective", and "not effective". Effective behavior indicates that the false killer whales swam directly away from the source of the sound soon after transmission. At the beginning of the experiments, the sound pressure level of the effective category was above about $170 \mathrm{dBrel} \mu \mathrm{Pa}$. This level rose as the number of experiments increased. A single pulse did not affect the behavior of the false killer whales. Pulseinterval and pulse-duration modulated sounds seemed to be more difficult to acclimate to than stable pulse sounds. To repel false killer whales, unexperienced sounds are thought to be more effective than experienced sounds.
\end{abstract}

High speed ships occasionally collide with cetaceans, endangering the safety both of those on board and of the cetaceans. Some method is needed to keep cetaceans away from cruising lanes.

Cetaceans use echolocation which resembles a sonar system. ${ }^{1,2}$ They are sensitive to the high frequency pulse waves used in echolocation. ${ }^{3)}$ Taiji fishermen in Wakayama Prefecture use the sounds of pulse waves created by striking an iron pipe to drive cetaceans into a small gulf. Hatakeyama $^{4)}$ reported that artificial ultrasonic pulse waves turned dalli's porpoises away from the source of the sound. Additionaally, acoustic signals travel so fast in the water that acoustic waves are thought to be useful in driving cetaceans away.

To find methods to drive cetaceans away from a cruising lane by sound, we observed the reactions of the false killer whale Pseudorca crassidens to various sounds in a net enclosure.

\section{Materials and Methods}

\section{Animals and Site}

Two female false killer whales were used. Body length was $395 \mathrm{~cm}$ (whale No. 1) and $345 \mathrm{~cm}$ (whale No. 2). They were caught on November 1990 in Taiji, Wakayama Prefecture, Japan. The whales ate fish thrown by a feeder voluntarily prior to the experiments which were conducted from 27
November to 5 December 1990 . The whales were kept in a net enclosure $(40 \mathrm{~m} \times 20 \mathrm{~m}$ in area, and $6 \mathrm{~m}$ deep) in Taiji Port (Fig. 1). Observers stood on top a of a scaffold $6 \mathrm{~m}$ above the water which was built beside the net enclosure. We recorded the behavior of the whales by $8 \mathrm{~mm}$ VTR.

\section{Transmitter}

Table 1 shows the 15 devices used and their wave form characteristics (frequency, pulse duration, pulse interval, and source level).

Low frequency pulsed sounds were generated by a water resistant iron drum (called a Bikkura; see Fig. 2), an iron pipe, and a water bomb. These low frequency sounds are audible. The Bikkura consisted of an iron plate $19 \mathrm{~cm}$ in diameter which was struck by a piston rod every $0.5 \mathrm{sec}$. The piston rod was driven by an electromagnet. Its source level was $214 \mathrm{~dB}$. The iron pipe was the same one as used in the Taiji whale fisheries (a $2.9 \mathrm{~m}$ pipe with a trumet $26 \mathrm{~cm}$ in diameter at one side). The trumpet extended horizontally when the pipe was submerged vertically. The trumpet emitted a sound when the pipe was struck by a hammer every $2 \mathrm{sec}$. The water bomb was $5 \mathrm{~cm}$ in diameter, globular in shape, and had $10 \mathrm{~g}$ of powder. We ignited it in the air and threw it in the water. It generated a single pulse wave with no pulse interval and no fixed frequency, and is indicated as-in Table 1.

*1 National Research Institute of Fisheries Engineering, Hasaki, Kashima, Ibaraki 314-04, Japan (赤烃友成, 畠山良己：水産工学研究所).

*2 Kawasaki Heavy Industry, Higashikawasaki, Chuo, Kobe 650-91, Japan (高津尚之：川崎重工業 (株)). 


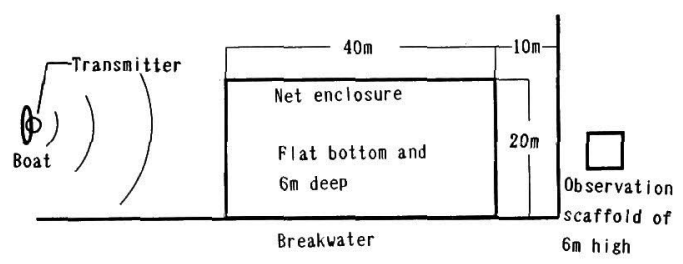

Fig. 1. Top view of the net enclosure.

Distances between the transmitter and the net enclosure were $0 \mathrm{~m}, 50 \mathrm{~m}, 100 \mathrm{~m}, 200 \mathrm{~m}$, and $300 \mathrm{~m}$.

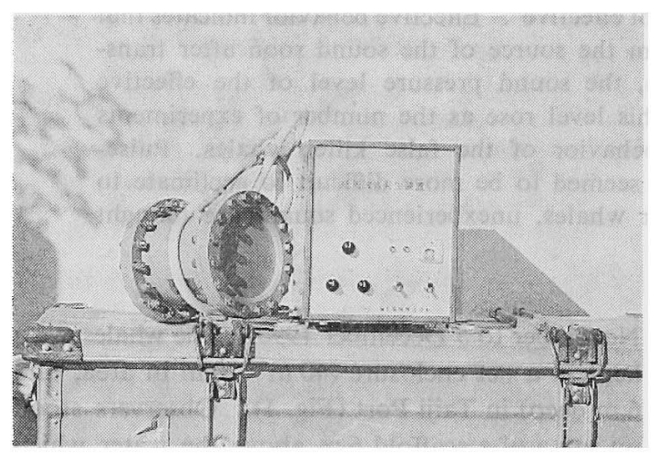

Fig. 2. Bikkura device.

The control box on the right was on the boat and the drum on the left was put in the water.
Stable ultrasonic pulse waves were emitted by PW-type devices. The device number (for example, 75 in PW-75) indicates the sound frequency of that device. The sounds were synthesized electronically and were emitted from a transmitter. The frequency, pulse interval, and pulse duration of this type of device were stable. PW-24-1,2,3 have the same frequency but with different pulse intervals and durations. The variation in transmitter directivity $\left(6^{\circ}\right.$ to $\left.18^{\circ}\right)$ depended on the kind of device.

Modulated ultrasonic pulse waves were emitted by Mark III-type devices and pseudo-echolocation device. Mark III-type devices varied in pulse intervals from $30 \mathrm{~ms}, 50 \mathrm{~ms}, 70 \mathrm{~ms}, 100 \mathrm{~ms}, 200 \mathrm{~ms}$, $300 \mathrm{~ms}, 400 \mathrm{~ms}, 500 \mathrm{~ms}$ and in pulse durations from 10 values $(1 \mathrm{~ms}, 2 \mathrm{~ms}, \cdots, 10 \mathrm{~ms})$. Each transmitted pulse differed in pulse interval and pulse duration. The frequency (for example 24 in Mark III-24) of these devices was fixed. Transmitter directivity ranged from $24^{\circ}$ to $72^{\circ}$. The pseudo-echolocation device simulated the echolocation signals of dalli's porpoise. Its sound included 20 to $50 \mathrm{kHz}$ frequency components. Selected pulse intervals varied from 10 to $226 \mathrm{~ms}$, and pulse durations from 1 to $109 \mathrm{~ms}$. The source level of this device was weaker than that of the

Table 1. Wave form characteristics of transmitter devices

\begin{tabular}{|c|c|c|c|c|}
\hline Device name & $\begin{array}{l}\text { Frequency range } \\
(\mathrm{kHz})\end{array}$ & $\begin{array}{l}\text { Pulse duration } \\
\text { (msec) }\end{array}$ & $\begin{array}{l}\text { Pulse interval } \\
\text { (msec) }\end{array}$ & $\begin{array}{c}\text { Source level } \\
(\mathrm{dBrel} \mu \mathrm{Pa})\end{array}$ \\
\hline \multicolumn{5}{|l|}{ Low frequency pulses } \\
\hline Bikkura & $.2-5.2$ & $\sim 1$ & 500 & 214 \\
\hline Iron pipe & $.2-5.2$ & $\sim 1$ & $\sim 2000$ & 205 \\
\hline Water bomb & - & $\sim 1$ & - & 213 \\
\hline \multicolumn{5}{|l|}{ Stable pulses } \\
\hline PW-24-1 & 24 & 10 & 100 & 209 \\
\hline PW-24-2 & 24 & 50 & 100 & 209 \\
\hline PW-24-3 & 24 & 480 & 920 & 209 \\
\hline PW-75 & 75 & 2 & 250 & 219 \\
\hline PW-115 & 115 & 2 & 250 & 218 \\
\hline PW-200 & 200 & 2 & 250 & 210 \\
\hline PW-mixed & $75+115$ & 2 & 250 & 219 \\
\hline \multicolumn{5}{|l|}{ Modulated pulses } \\
\hline Mark III -24 & 24 & $1-10$ & $30-500$ & 201 \\
\hline Mark III -50 & 50 & $1-10$ & $30-500$ & 204 \\
\hline Mark III -75 & 75 & $1-10$ & $30-500$ & 187 \\
\hline Mark III -mixed & $24+50+75$ & $1-10$ & $30-500$ & 204 \\
\hline Pseudo-echolocation & $20-50$ & $1-109$ & $10-226$ & 181 \\
\hline
\end{tabular}

Bikkura, iron pipe and pseudo-echolocation devices have complex wave forms within certain frequency component ranges (indicated by $20-50$ denoting $20 \mathrm{kHz}$ to $50 \mathrm{kHz}$ ).

+ in frequency range column denotes mixing of signal, Water bomb emits single pulse with no pulse interval nor certain frequency (indicated as - ). $\sim \mathrm{xx}$ means nearly equal $\mathrm{xx}$. Mark III -type devices have several pulse durations (indicated as minimum of pulse duration - maximum of pulse duration). Several pulse intervals are alse indicated the same way. Source level is the sound pressure level at a point $1 \mathrm{~m}$ from transmitter. 
other devices and its transmitter had no horizontal directivity.

Mixed pulses were also examined. We operated PW-75 and PW-115 on a boad simultaneously with PW-mixed experiments. Mark IIImixed consist complefely of Mark III type devices operated in the same way as the PW-mixed ones.

\section{System Operations}

Sounds were transmitted for a duration of three minutes at 20 minute intervals. The only exception was the water bomb, which was used only once during an experiment, so the duration of sound emission was short.

The directional hearing of the Atlantic bottlenose dolphin ${ }^{3)}$ is acute. As with false killer whales, its response to sounds is thought to depend on the direction of the animal's head. When there was little distance between the transmitter and the net enclosure, the variation of sound pressure level in the net enclosure was large. To avoid such a disturbance, we emitted the sound only when the whale swam within $20 \mathrm{~m}$ from the side of the net enclosure near the transmitter, and when the whale directed it head toward the transmitter. The direction of transmitter was also controlled toward the whale during the transmission.

A boat carried the transmitter to distances of $0 \mathrm{~m}, 50 \mathrm{~m}, 100 \mathrm{~m}, 200 \mathrm{~m}$, and $300 \mathrm{~m}$ from the net enclosure. Prior to the experiment, we measured each transmittter's sound pressure levels in the net enclosure when the device was set at the abovementioned distances. During actual experiments, the distance of the boat differed slightly from these distances. We measured the actual distance prior to each experiment and calibrated the sound pressure levels. In a later section, we discuss the sound pressure level in the net enclosure not in terms of the source level of each device, since the level heard by the whales is the level in the net enclosure. The operations of each transmitter are shown in Table 2 . Since " $n$ " in this table is the serial number of the experiment, we frequently refer to this number.

\section{Results}

Normally, the whales swam in circles inside the net enclosure at velocities of less than $1 \mathrm{~m} / \mathrm{s}$. The diameter of the circles ranged from $10 \mathrm{~m}$ to $20 \mathrm{~m}$ in the center of the net encolosure.

When the sound was transmitted, the whales swam directly away from the transmitter without approaching it. This behavior was not the normal behavior pattern. Whales swam in circles near the other side of the transmitter and usually did not approach it during transmission. We categorized this behavior as "effective". At some interval after the end of transmission, whales gradually moved to the center of the net enclosure, this interval varying from 0 to $10 \mathrm{~min}$. Thereafter their behavior showed the normal pattern. Different behavior was observed when the sound was transmitted. Whales continued to swim in circles but gradually distanced thermselves from the transmitter. We categorized this behavior as "somewhat effective". This behavior was also observed during the normal pattern once or twice per hour. So we categorized this behavior as "somewhat effective" only when it was observed just after the transmission. It there was no change in behavior due to the sound transmission, we categorized it as "not effective". The sound pressure level in the net encloure and the category of each experiment are shown in Table 2.

A typhoon struck Taiji on 30 November. During the ensuing storm surge, whale No. 2 escaped. Prior to the typhoon, both whales swam side by side, and their ordinary behavior showed no obvious differences compared with that of the single whale after the typhoon. Following the typhoon, we continued the experiment with whale No. 1 alone.

\section{Low Frequency Pulses}

Behavioral categories in response to low frequency sounds are shown in Fig. 3.

The Bikkura was tried three times. It was effective at $165 \mathrm{~dB}$ in the 30 th experiment. At this time, the transmitter of this deveice was at a depth of $2 \mathrm{~m}$. However, the same level sound ( $165 \mathrm{~dB}$ on the 28th experiment) was not effective when it was at $1 \mathrm{~m}$. The sea surface temperature was high that day. When there was a difference in vertical temperature, sound did not travel straight and the sound pressure levels tended to differ from the ideal value. The iron pipe was tried three times. It was not effective in the 25 th experiment. At this time, the boat drifted with the tide and it was difficult to keep the trumpet of the iron pipe directed toward the net enclosure. However, this device was effective in the two remaining (the 27 th and the 29th) experiments. The above two devices changed the behavior of the whales, but the water bomb was not effective de- 
Table 2. Order of experiments and behavioral category

\begin{tabular}{|c|c|c|c|c|c|c|c|c|c|}
\hline $\mathrm{n}$ & Date & Device name & $\begin{array}{l}\text { Sound } \\
\text { level at } \\
\text { whales } \\
\text { (dB) }\end{array}$ & $\begin{array}{l}\text { Behavi- } \\
\text { oral } \\
\text { Category }\end{array}$ & $\mathrm{n}$ & Date & Device name & $\begin{array}{l}\text { Sound } \\
\text { level at } \\
\text { whales } \\
\text { (dB) }\end{array}$ & $\begin{array}{c}\text { Behavi- } \\
\text { oral } \\
\text { Category }\end{array}$ \\
\hline \multicolumn{3}{|c|}{ November } & & & 33 & 2 & PW-24-2 & 171 & $\triangle$ \\
\hline 1 & 27 & Mark III -24 & 169 & $x$ & 34 & 2 & PW-24-2 & 171 & $\triangle$ \\
\hline 2 & 27 & Mark III -24 & 176 & $\triangle$ & 35 & 3 & PW-24-2 & 171 & $x$ \\
\hline 3 & 27 & Mark III -24 & 181 & $\triangle$ & 36 & 3 & PW-24-2 & 176 & $x$ \\
\hline 4 & 27 & Mark III -24 & 169 & $\times$ & 37 & 3 & PW-24-1 & 176 & $\triangle$ \\
\hline 5 & 27 & Mark III -24 & 163 & $x$ & 38 & 3 & Pseudo echolocation & 151 & $\triangle$ \\
\hline 6 & 27 & Mark III -50 & 145 & $x$ & 39 & 3 & Pseudo echolocation & 151 & $\Delta$ \\
\hline 7 & 27 & Mark III -50 & 165 & $\Delta$ & 40 & 3 & Pseudo echolocation & 153 & $x$ \\
\hline 8 & 27 & Mark III -75 & 152 & $x$ & 41 & 3 & Pseudo echolocation & 161 & $\Delta$ \\
\hline 9 & 27 & Mark III -75 & 161 & $x$ & 42 & 3 & PW-24-1 & 182 & $\triangle$ \\
\hline 10 & 27 & Mark III -75 & 167 & $\triangle$ & 43 & 3 & PW-24-2 & 182 & $\triangle$ \\
\hline 11 & 28 & Pseudo echolocation & 161 & 0 & 44 & 3 & Mark III -50 & 176 & $x$ \\
\hline 12 & 28 & Pseudo echolocation & 161 & 0 & 45 & 3 & Mark III -24 & 178 & 0 \\
\hline 13 & 28 & Pseudo echolocation & 146 & $x$ & 46 & 3 & Mark III -75 & 167 & $\Delta$ \\
\hline 14 & 28 & Pseudo echolocation & 141 & $x$ & 47 & 3 & Mark III -75 & 167 & $\Delta$ \\
\hline 15 & 29 & PW-200 & 151 & $x$ & 48 & 3 & Mark III -50 & 176 & $\triangle$ \\
\hline 16 & 29 & PW-115 & 173 & $\triangle$ & 49 & 3 & Mark III -24 & 177 & 0 \\
\hline \multirow[t]{3}{*}{17} & 29 & PW-75 & 161 & $\triangle$ & 50 & 4 & Pseudo echolocation & 161 & $x$ \\
\hline & 30 & Typhoon struck. & & & 51 & 4 & Pseudo echolocation & 161 & $x$ \\
\hline & & No. 2 escaped. & & & 52 & 4 & PW-75 & 161 & $x$ \\
\hline \multicolumn{3}{|c|}{ December } & & & 53 & 4 & PW-115 & 174 & $x$ \\
\hline 18 & 1 & PW-200 & 161 & $x$ & 54 & 4 & PW-75 & 173 & $x$ \\
\hline 19 & 1 & PW-115 & 179 & 0 & 55 & 4 & PW-75 & 199 & $\triangle$ \\
\hline 20 & 1 & PW-75 & 173 & 0 & 56 & 4 & Pseudo echolocation & 148 & $\triangle$ \\
\hline 21 & 1 & PW-200 & 162 & $x$ & 57 & 4 & $P W-75$ & 183 & $\triangle$ \\
\hline 22 & 1 & PW-115 & 173 & 0 & 58 & 4 & PW-75 & 172 & $x$ \\
\hline 23 & 1 & PW-75 & 161 & 0 & 59 & 4 & $\mathrm{PW}-115$ & 179 & $x$ \\
\hline 24 & 2 & Bikkura & 157 & $\triangle$ & 60 & 4 & PW-mixed & 180 & $\triangle$ \\
\hline 25 & 2 & Iron pipe & 174 & $x$ & 61 & 5 & Pseudo echolocation & 161 & $x$ \\
\hline 26 & 2 & Water bomb & 183 & $x$ & 62 & 5 & Pseudo echolocation & 161 & $x$ \\
\hline 27 & 2 & Iron pipe & 174 & 0 & 63 & 5 & Pseudo echolocation & 161 & $x$ \\
\hline 28 & 2 & Bikkura & 165 & $x$ & 64 & 5 & Mark III -mixed & 176 & 0 \\
\hline 29 & 2 & Iron pipe & 178 & 0 & 65 & 5 & Mark III -mixed & 170 & $\triangle$ \\
\hline 30 & 2 & Bikkura & 165 & 0 & 66 & 5 & Mark III -mixed & 163 & $x$ \\
\hline 31 & 2 & Water bomb & 186 & $x$ & 67 & 5 & PW-mixed & 183 & $\triangle$ \\
\hline 32 & 2 & PW-24-3 & 171 & $\Delta$ & 68 & 5 & PW-mixed & 183 & 0 \\
\hline
\end{tabular}

$\mathrm{n}$ is number of experiment, Experiment conducted November to December 1990.

$O$, effective; $\triangle$, somewhat effective; $x$, not effective.

spite a high sound pressure level above $180 \mathrm{~dB}$. This sound was different from the other sounds since it had only one pulse.

\section{Stable Pulses}

Most of the PW-24-type devices were somewhat effective (Fig. 4). The whale swam in circles, slowly distancing itself from the transmitter. PW24-2 was examined 4 times in succesion (from the 33rd to the 36th experiment). In the presvious two experiments, the device was somewhat effective. However, in the following two experiments, it was not. The sound pressure level in the not effective experiment (36th) was $5 \mathrm{~dB}$ higher than that of the somewhat effective experiment. This shows that the repetition of sound transmission affected the reaction of the whales. PW-24-1 was somewhat effective. This device had the same frequency as PW-24-2 but a different pulse interval and duration. The effects of the PW24-type devices were the same except that the experiments were successive.

PW-75 was effective or somewhat effective in the early series of experiments at about $160-170 \mathrm{~dB}$. 


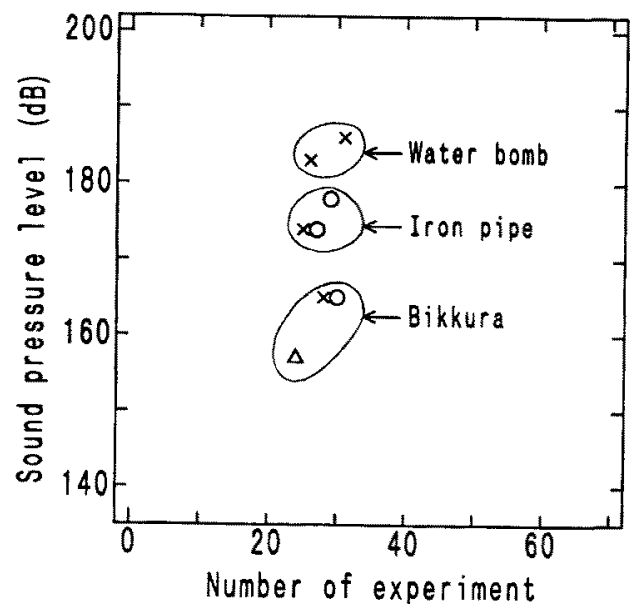

Fig. 3. Behavior during low frequency pulses (Bikkura, iron pipe, water bomb).

Ordinate denotes experiment number, $a b$ scissa shows the sound pressure level of the device in the net enclosure. Symbols, the same as in Table 2, are plotted at the sound pressure level and the experiment number. Some Bikkura experiments and the iron pipe experiments were effective. The water bomb was completely ineffective.

At the same order of sound pressure level in the later series of experiments, it was not effective. Even at a very high level ( $199 \mathrm{~dB}$ in the 55 th) the sound was only somewhat effective. PW-115 showed the same trend as PW-75 (Fig. 5). It was effective in the early part of the experiment, but the same order of sound levels were not effective in the later experiment. This shows that the effective threshold of PW-type devices went up as the number of the experiment increased.

PW-200 was not effective at all. This device emitted the highest frequency which is hard for the false killer whale to hear.

\section{Modulated Pulses}

Mark III-24 was somewhat effective at about $180 \mathrm{~dB}$ in the 2 nd and 3rd experiments (Fig. 6). This level also proved effective in the 45th and 49th experiments. The low level sound of this device (1st, 4th, 5th) was not effective. Mark III75 showed a trend similar to that of Mark III-24. Both devices were somewhat effective early and late in the experiments. They were not effective under the levels of $161 \mathrm{~dB}$ for Mark III-75 or $170 \mathrm{~dB}$ for Mark III-24. Mark III-50 was tested four times. In these early experiments, this device was somewhat effective, but it was not effective at low levels. In the late experiments, it was somewhat effective or not effective.

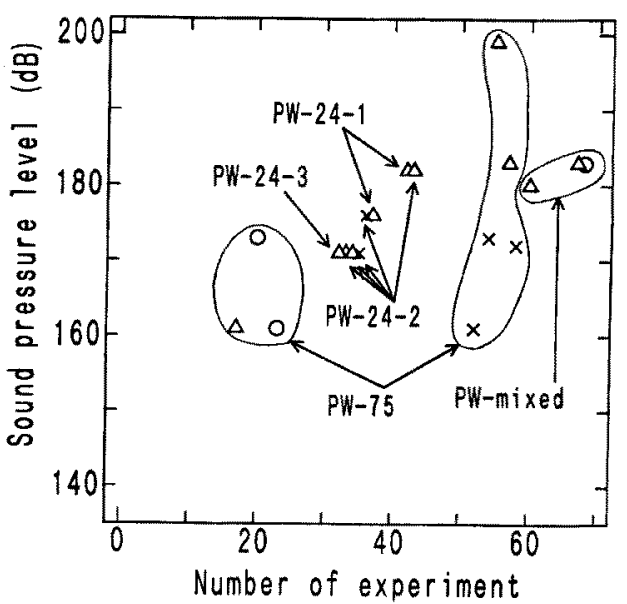

Fig. 4. Behavior during stable pulses (PW-24-1, PW-24-1, PW-24-2, PW-75, PW-mixed).

Symbols are the same as in Fig. 3. Most of the PW-24 devices were somewhat effective. However, PW-24-2 was not effective in the 35 th and 36 th after somewhat effective experiments (33rd and 34th). PW-75 was effective in the early experiments, but not in the later ones. Mixed pulse (PW-mixed consists of PW-75 and PW-115) was effective or somewhat effective in the later experiments.

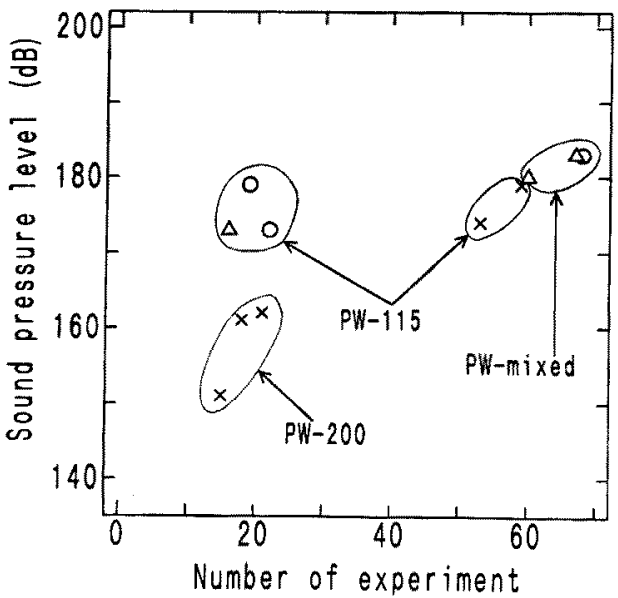

Fig. 5. Behavior during stable pulses (PW-115, PW-200, PW-mixed).

Symbols are the same as in Fig. 3 PW -115 was effective in early experiments, not in later ones. PW-200 was not effective, due to the whales' difficulty in hearing the $200 \mathrm{kHz}$ signal. 


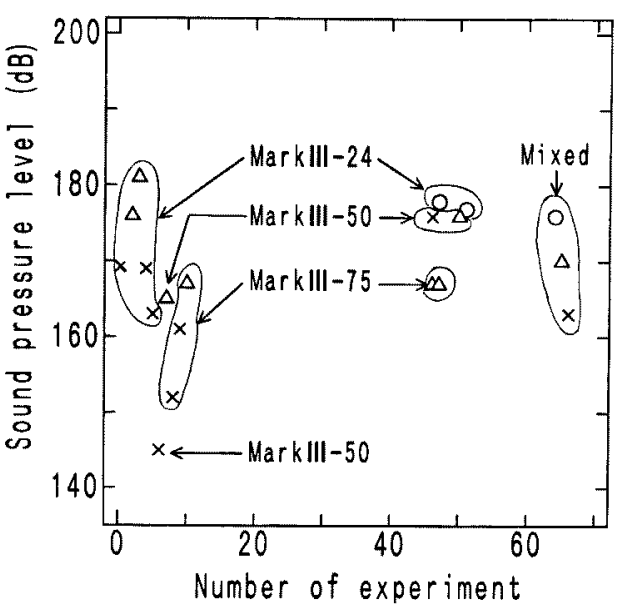

Fig. 6. Behavior during modulated pulses (Mark III -24, Mark III -50, Mark III -70, Mark III -mixed).

Symbols are the same as in Fig. 3. Single Mark III -type devices above 160 to $170 \mathrm{~dB}$ were effective or somewhat effective both early and late in experiments. Mixed pulse (Mark III -mixed consists of all Mark III -type devices) was effective or somewhat effective in the late experiments.

Mark III type devices did not change the effective threshold between early and late in the experiment. These devices modulated the pulse interval and duration.

We tried pseudo-echolocation 14 times with this largest of all the devices (Fig. 7). Early in the experiments (11th and 12th), the whales quickly avoided the device at a $161 \mathrm{~dB}$ sound. In the later experiment, the reaction of the whale gradually became less pronounced. The sound went from somewhat effective to not effective. In the 63rd experiment, the whale actually swam toward the device during transmission.

\section{Mixed Pulses}

Experiments using mixed devices were conducted at the end of the study.

Behavioral categories during the transmission of PW-mixed devices are shown at the same points in Fig. 4 and Fig. 5 for comparison with PW-type devices. The PW-mixed device was effective in spite of the later expermients. In the 60th experiment with this device, the whale swam away from the transmitter after swimming once in a circle. This reaction was evaluated as "somewhat effective", but the behavior bordered on

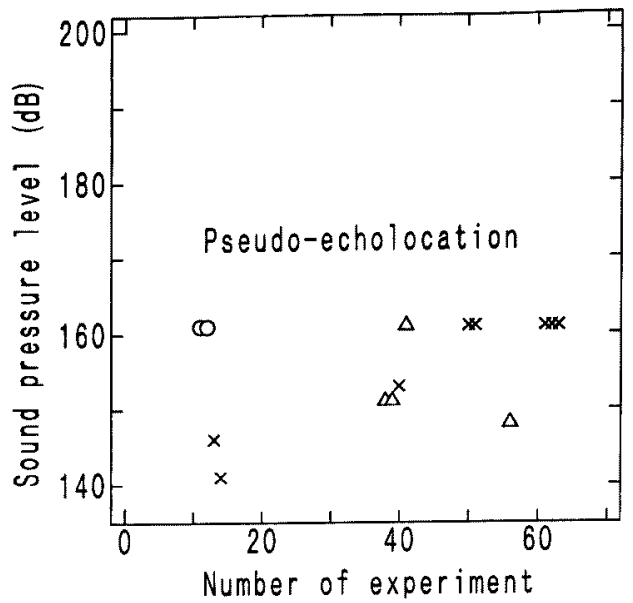

Fig. 7. Behavior during Pseudo-echolocation. Symbols are the same as in Fig. 3. Pseudoecholocation was initially effective at $161 \mathrm{~dB}$. After experiment 38 , the reaction became less pronounced.

"effective". On the other hand, only a PW-type device was somewhat effective (PW-24, PW-75) or not effective (PW-115) later in the experiments at the same order of the level as the PW-mixed device. As for the PW type devices, the effectiveness of the mixture of sounds differed from that of a single sound.

On the other hand, the effective threshold for Mark III-mixed was of the same order as that of single Mark III-24 type devices (Fig. 6). There were no obvious differences between Mark IIIand other Mark III devices.

\section{Discussion}

The determining parameters in the behavioral category of a false killeer whale are thought to be the sound pressure level and the number of experiments conducted. The level for the effective category seemed to chluster around $170 \mathrm{~dB}$ in the early experiments. We were unable to determine whether the effective threshold had a maximum limit after many transmission experiments, even though a level of about $200 \mathrm{~dB}$ seemed insufficient in itself to drive whales away in the later experiment.

The effective thresholds by stable pulses seems to increase in direct ratio to the number of experiments. This seems to indicate a pattern of acclimation in the whales. On the other hand, 
modulated sound seems to be difficult to acclimate to, since its effective threshold varied little from one experiment to the other. Mixed sound with stable pulses seems to be more effective than a single stable pulse. However, mixed sound with modulated pulses appears to have the same effect as a single modulated pulse. This suggests that complex sounds (modulated or mixted) are harder to acclimate to than stable sounds.

When experiments using a single device succeed (pseudo-echolocation and PW-24-2), the later experiments tend to results in ineffective behavior. This suggests that repeated sounds are soon acclimated to. However, repeated sound became sowewhat effective after several experiments with other devices. Unexperienced sounds are more effective than experienced sounds at the same sound pressure level. Effective sounds seem to require some novelty.

A single pulse device (water bomb) does not seem to affect the whale's behavior in spite of its high sound pressure level. Perhaps the whale is unable to discriminate the direction of the sound because of the single pulse signal.

Thomas $^{32}$ reported that a false killer whale is sensitive from $16 \mathrm{kHz}$ to $64 \mathrm{kHz}$. The PW-200 device which emitted a $200 \mathrm{kHz}$ signal was completely ineffective. It is thought that the whales did not hear the signal. However, we may also speculate that the PW-200 level was too low to drive the whales away. The PW-115 device was effective at $115 \mathrm{kHz}$, which was outside the sensitive range mentioned above. This sound was presumed to be effective due to its high sound pressure level. Low frequency sounds were just as effective as ultrasonic pulses. Pulse intervals and pulse durations also did not seem to be decisive, since there was little difference among behavioral responses to the sounds of PW-24-1,2 and 3, each of which had a different pulse interval and duration.

Frequency, pulse interval and pulse duration do not seem to be the decisive factor when a sound is heard by a whale. In general, unexperienced sounds above $170 \mathrm{~dB}$ and within a whale's sudible frequency are thought to drive a whale away at first. To repel whales, unexpreienced sounds are thought to be more effective than experienced ones.

These data on repelling whales deserve attention. A sound is heard or not depending on the sound level at a whale's location. When there was a vertical temperature change, the level of sound reaching a whale depended on the depth of the transmitter and the whale. Next, the hearing ability of the whale in a noisy environment ${ }^{6}$ is different from that in a calm sea. And a whale's sensitivity in the open ocean may be different from that in a net enclosure. Nevertheless, whales have to obtain information about their food and environment from the water sound, so one can expect wild whales to be more sensitive to sounds than captive ones.

\section{Acknowledgments}

We wish to thank the Taiji Fishery Cooperative Association. We are indebted to Mr. Yoshifumi Kai for managing the capture of the whales and the construction of the net enclosure, and to $\mathrm{Mr}$. Hiroaki Hodate and Mr. Takayuki Miyazaki for their support of our experiments.

\section{References}

1) A. N. Popper: Sound emission and detection by delphinds, in "Cetacean Behavior" (ed. by L. M. Herman), Robert E. Krieger Publishing Company, Florida, 1980, pp. 1-52.

2) C. Kamminga and J.G. Van Velder: Investigation on cetacean sonar VIII Sonar signals of Pseudorca crassidens in comparison with Tursiops truncatus. Aquatic Mammals, 13, 43-49 (1987).

3) J. A. Thomas, N. Chun, W. W. L. Au, and K. Pugh: Underwater audiogram of a false killer whale (Pseudorca crassidens), J. Acoust. Sac. Am., 84, 936-940 (1988).

4) Y. Hatakeyama: Research on developing techniques to avoid the incidental catch of marine mammals. INPFC Doc 2989 (1986).

5) W. W. L. Au and P. W. B. Moor: Receiving beam patterns and directivity indices of the Atlantic bottlenose dolphin Tursiops trunctaus. J. Acoust. Soc. Am., 75, 225-262 (1984).

6) J. A. Thomas and C. W. Turl: Detection abilities and signal characteristics of echolocating false killer whales (Pseudorca crassidens), in "Sensory Abilities of Cetaceans" (ed. by J. A. Thomas and R. Kastelein), Plenum Press, New Tork and London, 1990, pp. 321-334. 